\title{
Field Observation Research on 3207 Large Mining Height Faces Rib Spalling in Huoerxinhe Coalmine
}

\author{
Qiao Wei $i^{1,2, a}$ \\ ${ }^{1}$ National Key Laboratory of Gas Disaster Detecting, Preventing and Emergency Controlling, \\ Chongqing 400037, China; \\ ${ }^{2}$ Chongqing Research Institute Co., Ltd. of China Coal Technology and Engineering Group, \\ Chongqing 400037, China. \\ acqqiaowei@126.com
}

Keywords: Huoerxinhe coalmine, Large mining height, Rib spalling, Field observation.

\begin{abstract}
In order to further study Huoerxinhe coalmine 3207 large mining height faces rib spalling and complete the control management work, the laser rangefinder and visual observation method were used to observer the mining faces rib spalling and failing. The date(rib spalling depth, height, daily spalling range and so on) were recorded, and the main reason for 3207 working face spalling was analyzed. The result shows that Huoerxinhe coalmine 3207 large mining height faces rib spalling has three kinds of form that coal upper spalling(53\%), middle upper spalling(44\%) and whole coal spalling(3\%).3207 mining rib spalling failure mode is mainly shear slip, and the working face cycle pressure has a greater impact on the stability of coal wall. The geological structure, roof and floor nature, mining height and working face advancing rate are the major cause.
\end{abstract}

\section{Introduction}

With the increase of the mining height, the depth and the frequency of coal rib spalling will increase[1-2]. The serious rib spalling make the coal body lose their ability to support, and the roof pressure will transfer to the top bracket. Because of the unbalanced of the stent discontinuity, the phenomenon of bite planes and down racks would generate. The rib spalling makes the surface distance of front bracket increase. The roof will be apt to take the leak and it would form a wide range of spatial top[3]. It will cause serious roof accidents and great difficulties for safety mining face. Therefore, the in-depth study and control of the soft coal seam mining height rib spalling, and good management for coal rib spalling is not only the important content for the safe production and management, but also is the better economic guarantee for soft coal seam fully mechanized mining[4-5].

Huoerxinhe coal 3207 large mining height faces tendency length is $220 \mathrm{~m}$, strike length is $1389 \mathrm{~m}$. The coal seam is approximate level, the average thickness is $5.3 \mathrm{~m}$, the protodyakonov coefficient $\mathrm{f}$ is $0.5 \sim 0.6$ and the immediate roof is the carbonaceous mudstone with complex geological conditions. According to the roof classification standard (MT554-1996), the face roof is a typical loose thick coal seam broken roof. The working face occurred the large area of rib spalling and failing in overhand mining process between March 15,2013 to March 29,2013. It spent 15days to deal with the rib spalling and failing accidents and it seriously affected the normal back production. Therefore, it has on-site observations for the Huoerxinhe coal 3207 large mining height faces rib spalling, analyzes the reasons for its occurrence and it can provide technical support for the smooth and safe recovery of 3207 large mining height faces in Huoerxinhe coal.

Table1 The working face rock structure

\begin{tabular}{|c|c|c|c|c|c|}
\hline Position & $\begin{array}{c}\text { Thickness } \\
(\mathrm{m})\end{array}$ & $\begin{array}{c}\text { Poisson's } \\
\text { ratio }\end{array}$ & $\begin{array}{c}\text { Tensile } \\
\text { strength(MPa) }\end{array}$ & $\begin{array}{c}\text { Elastic } \\
\text { modulus(GPa) }\end{array}$ & $\begin{array}{c}\text { Density } \\
\left(\mathrm{Kg} / \mathrm{m}^{3}\right)\end{array}$ \\
\hline Level 1 & 3.8 & 0.34 & 2.97 & 8.67 & 2236 \\
\hline Level 2 & 3.6 & 0.31 & 2.88 & 13.8 & 2708 \\
\hline
\end{tabular}




\begin{tabular}{|c|c|c|c|c|c|}
\hline Level 3 & 1.0 & 0.32 & 0.1 & 2.97 & 1390 \\
\hline Level 4 & 1.0 & 0.34 & 2.97 & 8.67 & 2236 \\
\hline Level 5 & 3.4 & 0.34 & 3.14 & 27.6 & 2656 \\
\hline Level 6 & 0.5 & 0.34 & 2.97 & 8.67 & 2236 \\
\hline Level 7 & 3.7 & 0.31 & 2.88 & 13.8 & 2708 \\
\hline Level 8 & 0.6 & 0.32 & 0.1 & 2.97 & 1390 \\
\hline Level 9 & 4.4 & 0.31 & 2.88 & 13.8 & 2708 \\
\hline Level 10 & 0.4 & 0.32 & 0.1 & 2.97 & 1390 \\
\hline Level 11 & 1.9 & 0.31 & 2.88 & 13.8 & 2708 \\
\hline Level 12 & 5.0 & 0.34 & 3.14 & 27.6 & 2656 \\
\hline
\end{tabular}

\section{Mining faces rib spalling field observations}

The laser rangefinder and visual observation method are used to observer mining faces rib spalling and failing. The rib spalling is measured and recorded in daily maintenance classes, and the cutting height, cutting coal speed, working resistance support and other factors are analyzed on the impact of rib spalling and failing. Since May 13, 2013 to June 14, 2013, the 3207 large mining height faces rib spalling was measured in daily maintenance classes and the data of coal spalling depth greater than $400 \mathrm{~mm}$ was recorded, as shown in Table2 and Table3. Form the record date, the number of rib spalling is 67 and the rib spalling spread range is 262 brackets, and it more appeared among $40 \# \sim 100$ \# bracket.

Table2 Coal rib spalling depth and height

\begin{tabular}{|c|c|c|c|c|c|c|}
\hline Bracket range & $1 \# \sim 20 \#$ & $21 \# \sim 40 \#$ & $41 \# \sim 60 \#$ & $61 \# \sim 80 \#$ & $81 \# \sim 100 \#$ & $101 \# \sim 129 \#$ \\
\hline Requency & 2 & 9 & 22 & 17 & 11 & 6 \\
\hline Depth (m) & $0.4 \mathrm{~m}$ & 0.73 & 0.96 & 0.88 & 0.87 & 0.76 \\
\hline Height(m) & 0.95 & 2.11 & 2.1 & 2.35 & 2.21 & 2.16 \\
\hline
\end{tabular}

Table3 Coal rib spalling range greater than 10 date statistics

\begin{tabular}{|c|c|c|c|c|c|}
\hline Date & $\begin{array}{c}\text { Daily advance } \\
\text { degrees }(\mathrm{m})\end{array}$ & $\begin{array}{c}\text { Spalling } \\
\text { Rack }\end{array}$ & $\begin{array}{c}\text { Frequency(spalling } \\
\text { depth>600mm) }\end{array}$ & $\begin{array}{c}\text { Frequency(spalling } \\
\text { depth>1000mm) }\end{array}$ & $\begin{array}{c}\text { Average } \\
\text { depth (m) }\end{array}$ \\
\hline May 14 & 3.2 & 15 & $33.3 \%$ & $33.3 \%$ & 0.72 \\
\hline May 15 & 5.6 & 10 & $80.5 \%$ & $10.3 \%$ & 0.63 \\
\hline May 24 & 5.6 & 13 & $50 \%$ & $27.3 \%$ & 0.75 \\
\hline May 25 & 1.6 & 15 & $100 \%$ & $100 \%$ & 1.47 \\
\hline May 30 & 1.6 & 10 & $100 \%$ & $30 \%$ & 0.92 \\
\hline June 1 & 2.4 & 21 & 0 & $60 \%$ & 1.28 \\
\hline June 3 & 2.4 & 20 & $80 \%$ & $30 \%$ & 1.08 \\
\hline June 8 & 2.4 & 22 & $100 \%$ & $100 \%$ & 1.18 \\
\hline June 12 & 2.4 & 17 & $100 \%$ & $100 \%$ & 1.0 \\
\hline
\end{tabular}


It has three kinds of rib spalling form that coal upper spalling(53\%), middle upper spalling(44\%) and whole coal spalling(3\%), as shown in Fig.1.

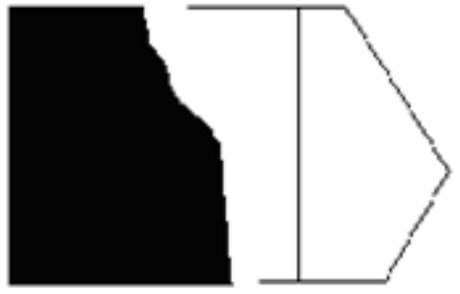

(a)upper spalling

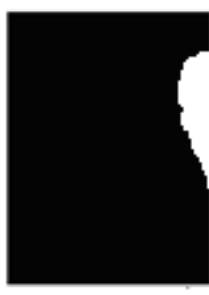

(b)middle upper spalling

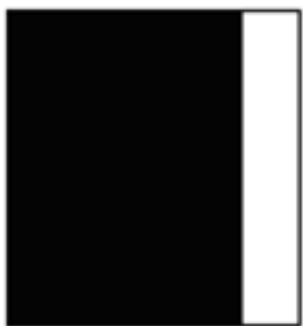

(c)whole spalling

Fig.1 Rib spalling sketch

Coal rib spalling failure modes are mainly shear slip and tensile fracture. Coal wall cracking failure often occurs in the brittle hard coal, piece for the main reason is that under the effect of roof pressure, within the coal wall transverse tensile stress, and transverse tensile stress by the deformation and hard to release, so when the transverse tensile stress is greater than the tensile strength of coal, coal wall cracking destruction, often accompanied by cracking sound. For the soft coal seam, the weight of coal and roof pressure, and also within the coal wall transverse tensile stress, but the lateral of the soft coal seam and creep deformation will release the transverse tensile stress due to compression, eventually because of coal within the wall shear stress is greater than the shear strength and shear sliding failure. No matter what the situation is, the spalling depth refers to the coal cave of maximum depth. Combined with the seam structure and field measurement of 3207 mining height, the 3207 mining rib spalling failure mode is mainly shear slip.

\section{Mining faces rib spalling cause analysis}

It can be seen from the above piece for data statistics that the 3207 working face in the time period for the case is not very serious. The main reason is that advancing to working face can rise to reduce the coal wall plate help depth and alleviate the coal wall piece in $3^{\circ} \sim 6^{\circ}$ bends down. But it can still find some laws from the statistics data. From the Table1, the working face upper spalling is much better than the middle and lower, and the coal spalling is the worst within the $41 \# \sim 60 \#$ stents, and the average depth is $0.96 \mathrm{~m}$. This is the face tendency to coincide with the mine pressure regularity.

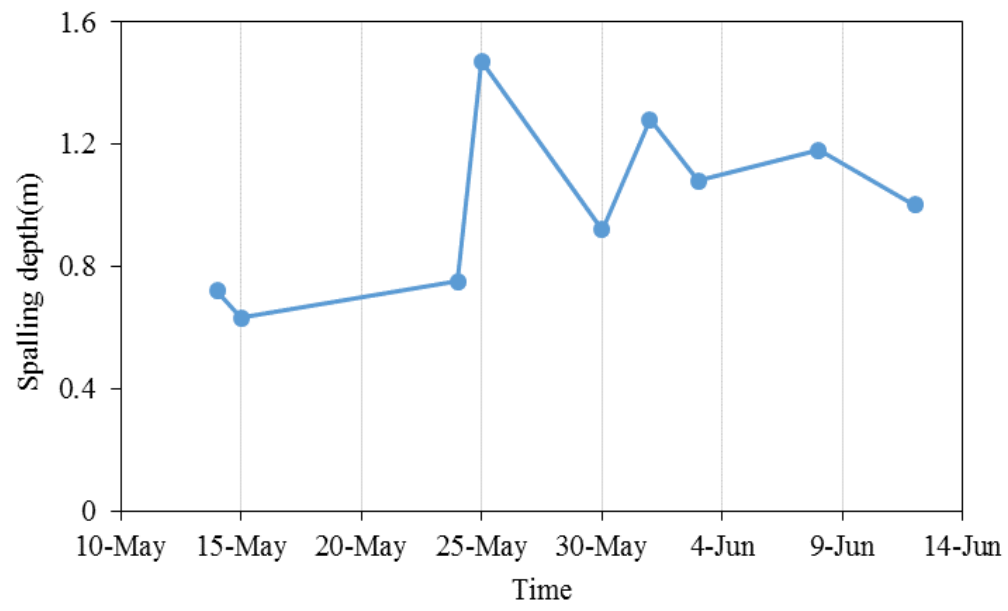

Fig2. The average daily spalling depth

From the Fig.2, on May 25 the working face advancing speed is $2.4 \mathrm{~m} / \mathrm{d}$, and the average daily spalling depth is to 1.22 times that of the original, and spalling range also increases to 1.35 times that of the original. This is because the advancing speed decreases, face periodic weighting interval 
becomes short, periodic weighting number increases, and it causes the coal wall for larger number and depth. Combined with periodic weighting interval analysis, it shows that during experience cycle on May 15, May 20, on May 27, June 5, June 12 the working face spalling range are greater than 10 bracket,and the average daily depth is more than $0.6 \mathrm{~m}$, significantly greater than the non-periodic weighting period. So the periodic weighting has greater effect to the stability of coal wall.

Through the observation of site production, it found that a large part of coal wall spalling is in the coal shearer cutting disturbance. Under the disturbance of coal winning machine cutting coal, when wooders pack up help plates, coal winning machine in front of the coal wall can be spalling. When the coal is hard, spalling falling coal are relatively complete, easily stuck in scraper conveyor starting place, so it needs artificial coarse coal with pneumatic to pick broken. It not only affects the normal coal winning machine, and also affects the safety for workers.

The main reason of 3207 working face spalling are as follows:

(1) The complex geological structure, fault, fold and coal seam occurrence change sharply, coal measures strata sedimentary formation of the joint, crack and other abnormal geological structure impact frequency.

(2) Thick coal seam sections of false roof, roof sandstone fissure water weakening roof rock strength, cause easily broken roof, soft coal at the same time, coal seam is easy to spalling.

(3) Large mining height are broken, mine pressure increase, plastic zone width increases, coal wall during the mining of coal seam roof and coal wall pressure, fracture easily broken roof, roof caving, coal quality soft hard uneven development, easy to spalling.

(4) With the influence of strata occurrence, face tilted back mining area is more, the local segment elevation at $12^{\circ}$, cut after the coal of coal wall slightly forward, top coal formed its own gravity refers to the component of the mined-out area, a surface coal wall stability and decreased with increment of overhead mining angle, predisposes to spalling.

(5) Due to the stop production, the working face advancing speed becomes slowly, stress concentration is caused by mining, coal wall abutment pressure increases, fracture development, further to spalling caving.

\section{Conclusion}

The laser rangefinder and visual observation method are used to observer the mining faces rib spalling and failing. The date(rib spalling depth, height, daily spalling range and so on) were recorded, and the main reason for 3207 working face spalling was analyzed.

(1) 3207 large mining height faces rib spalling has three kinds of form that coal upper spalling(53\%), middle upper spalling(44\%) and whole coal spalling(3\%).

(2) 3207 mining rib spalling failure mode is mainly shear slip, and the working face cycle pressure has a greater impact on the stability of coal wall.

(3) The geological structure, roof and floor nature, mining height and working face advancing rate are the major reasons to cause the rib spalling.

\section{References}

[1] M.G. Qian, J.L. Xu: Journal of China Coal Society, (1996) No.3, p.225-230. (In Chinese).

[2] J.C. Wang: Journal of China Coal Society, (2007) No.8, p.785-788. (In Chinese).

[3] X.W. Yin, S.H. Yan, Y. An: Journal of Mining and Safety Engineering, (2008) No.2, p.222-225. (In Chinese).

[4] Z.Q. Song, S.K. Liang, J.Q. Tang: Journal of Hunan University of Science and Technology (Natural Science Edition), (2011) No.1, p.1-4. (In Chinese).

[5] Z.H. Wang, J.H. Yang, H. Meng: Journal of China Coal Society, (2015) No.1, p.42-49. (In Chinese). 